Original Research Article

\title{
Effectiveness and safety of lactulose retention enema in cirrhotic patients with grade 3 or grade 4 hepatic encephalopathy
}

\author{
Kaushal Madan ${ }^{1}$, Praveen Sharma ${ }^{2}$, Neeraj Saraf ${ }^{3}$, Sanjay Choudhari ${ }^{4}$, Dyotona Sen Roy $^{4}$
}

${ }^{1}$ Department of Digestive and Liver Diseases, Artemis Hospital, Haryana, India ${ }^{2}$ Department of Gastroenterology, Sir Ganga Ram Hospital, New Delhi, India ${ }^{3}$ Department of Gastroenterology, Medanta-The Medicity, Haryana, India ${ }^{4}$ Department of Medical Affairs, Abbott India Limited, Goregoan, Mumbai, Maharashtra, India

Received: 05 December 2016 Revised: 08 December 2016 Accepted: 27 December 2016

*Correspondence to: Dr. Sanjay Choudhari, Email: sanjay.choudhari@abbott.com

Copyright: (C) the author(s), publisher and licensee Medip Academy. This is an openaccess article distributed under the terms of the Creative Commons Attribution NonCommercial License, which permits unrestricted noncommercial use, distribution, and reproduction in any medium, provided the original work is properly cited.

\section{ABSTRACT}

Background: Hepatic encephalopathy (HE) is a complex, reversible neuropsychiatric syndrome. The present study evaluated the clinical effectiveness and safety of lactulose retention enema for the treatment of Grade 3 or 4 HE (West Haven Criteria, WHC) in Indian patients.

Methods: This retrospective, open-label, uncontrolled cohort study was conducted at three study centers in India. Patients of either gender (18-65 years) admitted to the hospital with liver cirrhosis having Grade 3 or 4 HE were included. The primary endpoint was to evaluate complete reversal of Grade 3 and $4 \mathrm{HE}$ after $24 \mathrm{~h}$ and $48 \mathrm{~h}$. The secondary endpoints were grade shift at 24 and $48 \mathrm{~h}$ before and after administration of lactulose enema, time to complete reversal of Grade 3 or $4 \mathrm{HE}$, and mortality. Safety was also evaluated.

Results: Overall, retrospective records of 50 patients were evaluated. Complete reversal of Grade 3 or $4 \mathrm{HE}$ was observed in a statistically significant $(\mathrm{p}<0.0001)$ proportion $(95 \%$ confidence interval) of patients at $24 \mathrm{~h}(\mathrm{n}=40,80 \%$ [66. 3\%-90.0\%]) and $48 \mathrm{~h}(\mathrm{n}=45,90 \%$ [78. 2\%-96.7\%]) after treatment. After $24 \mathrm{~h}$ of treatment, majority of the patients were noted with Grade $2(78 \%)$ HE. Further improvement was noted after $48 \mathrm{~h}$ of treatment with majority of the patients having Grade 2 (40\%) and Grade 1 (48\%) HE. Mean (SD) time for complete reversal of Grade 3 or $4 \mathrm{HE}$ was $25.39 \pm 8.85 \mathrm{~h}$ after treatment. All death cases observed $(n=6,12.0 \%)$ were assessed as unrelated to the treatment by the investigator, but rather related to the underlying disease and/or precipitating factors. Four non-serious adverse drug reactions in two patients and one rectal device-associated complication in one patient were noted during the patient record reviews.

Conclusions: Lactulose retention enema was clinically effective and resulted in complete reversal of Grade 3 or $4 \mathrm{HE}$ in the majority of patients. It was overall well-tolerated.

Keywords: Complete reversal, Grade 3 and Grade 4 Hepatic encephalopathy, Hepatic encephalopathy, Hospitalization, Lactulose retention enema, West haven criteria

\section{INTRODUCTION}

Hepatic encephalopathy (HE) is a complex, reversible neuropsychiatric syndrome, characterized by changes in personality, consciousness, behaviour, and neuromuscular function. Clinical manifestations range from subtle abnormalities detectable only by psychometric testing to overt coma. ${ }^{1}$ It is a common complication in patients with liver cirrhosis, with prevalence varying between $30 \%$ and $45 \%$ in these patients. $^{2}$

Diagnosis of HE is done on the basis of West Haven Criteria (WHC) which is considered as the gold standard. WHC grades the clinical condition of HE between Grade 0 to 4 depending upon the degree of mental state disturbance. While minimal and Grade $1 \mathrm{HE}$ are referred as "covert HE", Grade 2-4 HE are called as "overt HE" collectively. Overt HE is a common complication of liver 
cirrhosis and its prevalence varies between $30-40 \%$ in cirrhotic patients. ${ }^{3}$ Overt HE makes patients incapable of self-care and may result in hospitalization. ${ }^{4}$

HE not only results in a diminished quality of life, but confers a poor prognosis in patients with underlying liver cirrhosis. ${ }^{1,3}$ Around $64 \%$ mortality has been observed in patients with HE. ${ }^{1}$ In addition, Grade 3-4 HE patients were found to have a $66 \%$ greater risk of mortality as compared to patients without HE in a 90-day period prior to liver transplantation. ${ }^{5}$

At present, the pathophysiology of $\mathrm{HE}$ is not fully understood and there are no internationally accepted standards for the management of this condition. Pharmacological treatment of HE aims at decreasing the production and absorption of ammonia in the gut via administration of drugs such as non-absorbable disaccharides (lactulose and lactitol), rifaximin, neomycin, metronidazole, ammonia scavengers, Lornithine-L-aspartate (LOLA), and probiotics. However, sufficient data is not available to support the use of most of these drugs and antibiotics like metronidazole are associated with ototoxicity, nephrotoxicity, neurotoxicity and gastrointestinal upset in continuous long-term use and neomycin is associated with ototoxicity and nephrotoxicity. ${ }^{3,4,6-8}$ According to the clinical practice guidelines for the management of HE by the American Association for the Study of Liver Disease (AASLD) and European Association for the Study of the Liver (EASL), lactulose represents the first-line treatment for $\mathrm{HE}^{3}$

Lactulose reduces the production of ammonia, decreasing its levels in colon and portal blood, and increases the nitrogen excretion from the body. ${ }^{9}$ As a result, treatment with lactulose leads to clinical improvements in $\mathrm{HE}$ within few hours of treatment. ${ }^{10-13}$ Currently, lactulose is recommended as an oral formulation in $\mathrm{HE}$ with appropriate dose titrations for producing at least two soft stools every day. ${ }^{3}$ However, this is not possible for Grade 3-4 patients of HE who are in the state of semi-stupor or coma. Therefore, such patients are treated with lactulose retention enemas or via nasogastric tube. ${ }^{7}$ However, data is limited to establish the effectiveness and safety of lactulose retention enema in HE, specifically in Indian population with cirrhosis. Data available regarding the administration of lactulose enemas date back to 1970s. Moreover, there is no published data on the efficacy and safety of lactulose retention enemas in a large patient group. ${ }^{10-14}$

Recently, a nationwide survey was conducted in Indian physicians which showed that $62 \%$ of the physicians used lactulose enema in HE patients, and considered it to be as good as giving oral lactulose or via nasogastric tube. ${ }^{15}$ Therefore, the present study was undertaken to further evaluate the clinical effectiveness and safety of lactulose retention enema in the treatment of cirrhotic patients with Grade 3 or 4 (WHC) HE in India.

\section{METHODS}

This retrospective, open-label, uncontrolled cohort study was conducted from 30 Dec 2015 to 16 Mar 2016 at three study centers across India namely Artemis Hospitals, Gurgaon; Sir Ganga Ram Hospital, New Delhi; and Medanta -The Medicity, Gurgaon.

The study was conducted in accordance to International Conference on Harmonization (ICH) and Declaration of Helsinki. The study protocol and amendments were reviewed and approved by the ethics committee at each site, with respect to ethical, scientific, and medical appropriateness of the study. The study has been registered on clinical trials.gov. with reference number NCT02377947.

\section{Inclusion and exclusion criteria}

Patients of either gender between 18 and 65 years of age admitted to the hospital with liver cirrhosis having Grade 3 or $4 \mathrm{HE}$ and treated with lactulose retention enema within $48 \mathrm{~h}$ of onset of Grade 3 or $4 \mathrm{HE}$ were included in the study. Patients who were treated with agents other than lactulose retention enema for Grade 3 or $4 \mathrm{HE}$, had significant concomitant diseases, had a major neuropsychiatric illness, or had been contraindicated to lactulose (including hypersensitivity to the active substance or to any of the ingredients, galactosemia, gastrointestinal obstruction, digestive perforation, or risk of digestive perforation) were excluded from the study.

\section{Study treatments}

This study was conducted retrospectively and lactulose retention enema was the mainstay of treatment in cirrhotic patients with Grade 3 or 4 HE. A similar administration protocol for the dosing of lactulose retention enema was followed in all three study centers, which has been described for the rectal administration of lactulose (India): $300 \mathrm{~mL}$ of lactulose mixed with 700 $\mathrm{mL}$ of potable water was used as a retention enema; the enema was retained for 30-60 minutes and repeated every 4-6 h until the patient was able to take oral medication. The hospital records of the preceding six months were examined to identify the patients for inclusion in study and these records were used for further data analysis.

\section{Study endpoints}

The primary endpoint of the study was to evaluate the percentage of patients with complete reversal of Grade 3 or $4 \mathrm{HE}$ (patients shifting $\leq$ Grade $2 \mathrm{HE}$ ) after treatment with lactulose retention enema. The secondary endpoints included grade shift at 24 and $48 \mathrm{~h}$ before and after administration of lactulose retention enema, time to complete reversal of Grade 3 and $4 \mathrm{HE}$, and mortality in patients treated with lactulose retention enema. 
Exploratory endpoints included reduction in blood ammonia level from baseline after administration of lactulose retention enema, time taken for the same and duration of hospital stay due to HE.

Safety of the lactulose retention enema was also evaluated (adverse drug reactions [ADRs] and complications, defined as potential adverse effects associated with the use of rectal device).

\section{Statistical analysis}

\section{Sample size calculation}

To evaluate the effectiveness and safety of lactulose retention enema for the treatment of cirrhotic patients with Grade 3 or $4 \mathrm{HE}$, at least 50 patients were required to be included in analysis. This approximation was made assuming two-sided, 5\% level of significance, at least $90 \%$ patients (expected proportion $=\mathrm{P}$ ) who were expected to demonstrate complete reversal of Grade 3 and $4 \mathrm{HE}(\leq$ Grade 2$)$ after receiving treatment with lactulose retention enema, and a precision of $8.32 \%$.

\section{Analysis set}

Per-protocol analysis was performed for all the primary, secondary, and exploratory end-points.

\section{Statistical methods}

Demographic data were summarized using number of patients (n) and percentages (\%). Continuous demographic variables were summarized as mean and standard deviation (SD), median, minimum, and maximum. For primary endpoint analysis, inferential statistics chi-square test was used to assess complete reversal of Grade 3 and $4 \mathrm{HE}$ ( $\leq$ Grade 2) after treatment with lactulose retention enema. For secondary endpoints analysis, inferential statistics chi-square test was used to assess shift in grade from baseline to 24 and $48 \mathrm{~h}$ after treatment. The time to complete reversal of Grade 3 and 4 $\mathrm{HE}$ after administration of lactulose retention enema was summarized as number of patients, mean, SD, median, minimum and maximum. Mortality in patients treated with lactulose retention enema was summarized using number and percentage. All safety data were analyzed descriptively on safety set.

\section{RESULTS}

\section{Patients}

Overall, 50 patients were included from all the three study centers. Mean age of the patients was $48.38 \pm 10.18$ years; majority of them were men $(n=40,80 \%)$. The study included $46 \%(n=23)$ patients with alcoholic liver disease and $38 \%(n=19)$ patients who had non-alcoholic fatty liver disease. A total of $24 \%(n=12)$ patients had viral hepatitis (amongst the patients of viral hepatitis, hepatitis B: $41.7 \%$ and hepatitis C: $41.7 \%$ ) and one patient $(2 \%)$ had autoimmune and cryptogenic cirrhosis.

All the patients $(n=50)$ were administered lactulose retention enema in right lateral position. In total, 253 lactulose enema administrations were given to the 50 patients enrolled in the study. The duration of retention enema was 30 minutes in $43(86 \%)$ patients and 60 minutes in $10(20 \%)$ patients (sum of the patients was not equal to all the enrolled patients due to different interval retention enemas provided to the patients). The detailed baseline characteristics are presented in Table 1.

\section{Primary endpoints}

Complete reversal of Grade 3 and 4 HE after administration of lactulose retention enema

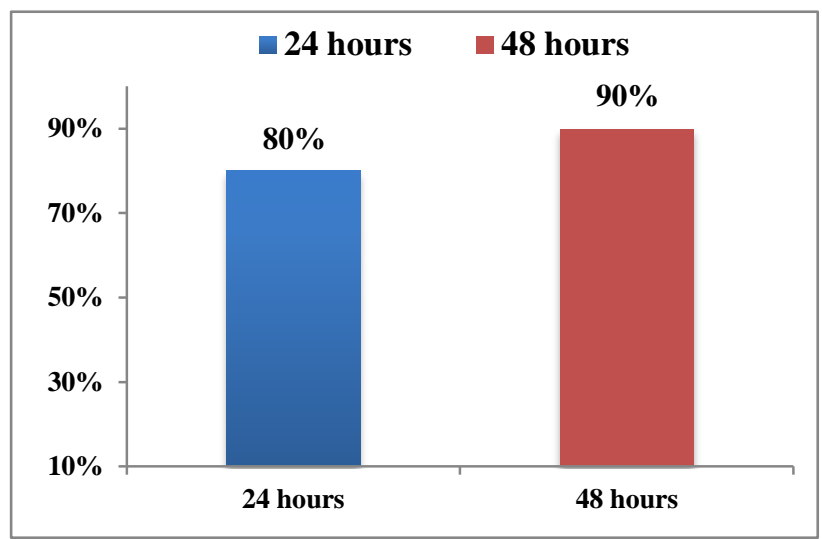

p-value derived by comparison with baseline $(n=50)$

\section{Figure 1: Complete reversal of Grade 3 and Grade 4 HE after 24 and $48 \mathrm{~h}$ of treatment with lactulose retention enema.}

Number of patients noted with Grade 3 and 4 HE after 24 $\mathrm{h}$ and $48 \mathrm{~h}$ of treatment with lactulose retention enema were compared with the number of patients having Grade 3 and $4 \mathrm{HE}$ at the baseline. Complete reversal of Grade 3 and $4 \mathrm{HE}$ was observed in a statistically significant ( $p<0.0001)$ proportion of HE patients $(\mathrm{n}=40,80 \%$ [66.28$89.97]$ ) after $24 \mathrm{~h}$ of treatment with lactulose retention enema. Similar trend was observed after $48 \mathrm{~h}$ of treatment wherein a statistically significant proportion $(\mathrm{p}<0.0001)$ of Grade 3 and $4 \mathrm{HE}$ patients achieved the complete reversal ( $n=45,90 \%$ [78.19-96.67] Figure 1). At baseline, $45(90 \%)$ patients had Grade $3 \mathrm{HE}$, out of whom complete reversal was noted in $39(86.6 \%)$ patients after $24 \mathrm{~h}$ and $43(95.5 \%)$ patients after $48 \mathrm{~h}$ of treatment. On the other hand, $5(10 \%)$ patients had Grade $4 \mathrm{HE}$ at baseline, and complete reversal was noted in $1(20 \%)$ patient after $24 \mathrm{~h}$ and $2(40 \%)$ patients after $48 \mathrm{~h}$ of treatment (Table 2). 
Table 1: Demographic and baseline characteristics of the patient population.

\begin{tabular}{|c|c|}
\hline Demographic parameter & Patients $(\mathrm{n}=\mathbf{5 0})$ \\
\hline Age in years $($ Mean $\pm \mathrm{SD})$ & $48.38 \pm 10.18$ \\
\hline \multicolumn{2}{|l|}{ Gender, n (\%) } \\
\hline Female & $10(20.0)$ \\
\hline Male & $40(80.0)$ \\
\hline Height in $\mathrm{cm}($ Mean $\pm \mathrm{SD})$ & $165.1 \pm 8.28$ \\
\hline Weight in $\mathrm{kg}($ Mean $\pm \mathrm{SD})$ & $66 \pm 8.92$ \\
\hline Smoking history, $\mathrm{n}(\%)$ & $17(34.0)$ \\
\hline Alcohol history, n (\%) & $23(46.0)$ \\
\hline Total number of patients who had a history of HE, n (\%) & $7(14.0)$ \\
\hline Total number of patients who had any medical history, n (\%) & $43(86.0)$ \\
\hline \multicolumn{2}{|l|}{ Etiology of cirrhosis } \\
\hline Total number of patients who had alcoholic liver disease, $\mathrm{n}(\%)$ & $23(46.0)$ \\
\hline Total number of patients who had non-alcoholic fatty liver disease, $\mathrm{n}(\%)$ & $19(38.0)$ \\
\hline Total number of patients who had viral hepatitis, $\mathrm{n}(\%)$ & $12(24.0)$ \\
\hline Total number of patients who had autoimmune disease, n (\%) & $1(2.0)$ \\
\hline Total number of patients who had cryptogenic cirrhosis, n (\%) & $1(2.0)$ \\
\hline \multicolumn{2}{|l|}{ Hospitalization status of patients } \\
\hline Total number of patients who had first episode of HE & $43(86.0)$ \\
\hline \multicolumn{2}{|l|}{$\begin{array}{l}\text { Patients grade of HE as per West Haven criteria at the time of admission in the } \\
\text { hospital (Patients who had first episode of HE) }\end{array}$} \\
\hline Grade 3 & $38(88.4)$ \\
\hline Grade 4 & $5(11.6)$ \\
\hline Total number of patients who had any precipitating factors of $\mathrm{HE}$ & $35(70.0)$ \\
\hline Dehydration & $4(11.4)$ \\
\hline GI Bleeding & $8(22.9)$ \\
\hline Protein overload & $4(11.4)$ \\
\hline Constipation & $19(54.3)$ \\
\hline SBP infection & $3(8.6)$ \\
\hline Skin infection & $3(8.6)$ \\
\hline Soft tissue infection & $1(2.9)$ \\
\hline Pulmonary infection & $11(31.4)$ \\
\hline UTI & $6(17.1)$ \\
\hline Other condition & $10(28.6)$ \\
\hline Number of previous episodes of HE (n) & $7(14.0)$ \\
\hline Total number of patients treated with lactulose retention enema, n $(\%)^{*}$ & $50(100)$ \\
\hline \multicolumn{2}{|l|}{ Position for the administration of lactulose retention enema } \\
\hline Right Lateral position & $50(100)$ \\
\hline \multicolumn{2}{|l|}{ Duration of retention enema*\# } \\
\hline 30 mins & $43(86.0)$ \\
\hline 60 mins & $10(20.0)$ \\
\hline Others & $1(2.00)$ \\
\hline Blood ammonia level (mcg/dL, n) & 28 \\
\hline Mean (SD) & $125.4(46.55)$ \\
\hline
\end{tabular}

GI = Gastrointestinal; HE = Hepatic encephalopathy; SBP = Spontaneous bacterial peritonitis; SD = Standard deviation; UTI = Urinary tract infection

*sum of the patients not equal to all the enrolled patients due to different interval retention enemas provided to the patients

\# number of administrations in patients (the total number of lactulose enema administrations were 253 in overall 50 patients)

\section{Secondary endpoints}

HE grade shift from baseline to 24 and $48 \mathrm{~h}$ post treatment
Out of 45 patients noted with Grade $3 \mathrm{HE}$ at baseline, 38 (84.4\%) patients shifted to Grade 2, $1(2.2 \%)$ patient shifted to Grade 1, while 6 (13.3) patients were still noted with Grade $3 \mathrm{HE}$ after $24 \mathrm{~h}$ of treatment. Further improvement was noted after $48 \mathrm{~h}$ of treatment with majority of the patients being noted with Grade $2(n=18$, 
$40 \%)$ and Grade $1(n=24,53.3) \mathrm{HE} ; 1(2.2 \%)$ patient was noted with Grade 0 and 2 (4.4\%) patients were noted with Grade 3. On the other hand, out of 5 patients noted with Grade $4 \mathrm{HE}$ at baseline, $2(40 \%)$ patients shifted to Grade 3, $1(20 \%)$ patient shifted to Grade 2, while $2(40 \%)$ patients were still noted with Grade $4 \mathrm{HE}$ after $24 \mathrm{~h}$ of treatment. After $48 \mathrm{~h}$ of treatment, $2(40 \%)$ patients shifted to Grade 2, 1 (20\%) patient was noted with Grade 3 , and $2(40 \%)$ patients were still noted with Grade $4 \mathrm{HE}$ (Figure 2 and Figure 3).

Table 2: Assessment of grade shifts in HE grade from baseline to 24 and $48 \mathrm{~h}$ (before and after administration of lactulose retention enema).

\begin{tabular}{|c|c|c|}
\hline Shift in HE Grade & $\begin{array}{l}n \\
(\%)\end{array}$ & $\begin{array}{l}\text { p- } \\
\text { value*** }\end{array}$ \\
\hline \multicolumn{3}{|l|}{ From baseline to $24 \mathrm{~h}$} \\
\hline $\begin{array}{l}\text { Total number of patients who had } \\
\text { HE Grade } 3 \text { at baseline }\end{array}$ & $\begin{array}{l}45 \\
(90.0)\end{array}$ & \\
\hline $\begin{array}{l}\text { Total number of patients who } \\
\text { shifted from HE Grade } 3 \text { to } \leq 2 \\
\text { Grade* }\end{array}$ & $\begin{array}{l}39 \\
(86.6)\end{array}$ & $<0.0001$ \\
\hline $\begin{array}{l}\text { Total number of patients who had } \\
\text { HE Grade } 4 \text { at baseline }\end{array}$ & $\begin{array}{l}5 \\
(10.0)\end{array}$ & \\
\hline $\begin{array}{l}\text { Total number of patients who } \\
\text { shifted from HE Grade } 4 \text { to } \leq 2 \\
\text { Grade* }\end{array}$ & $\begin{array}{l}1 \\
(20.0)\end{array}$ & $<0.0001$ \\
\hline \multicolumn{3}{|l|}{ From baseline to $48 \mathrm{~h}$} \\
\hline $\begin{array}{l}\text { Total number of patients who had } \\
\text { HE Grade } 3 \text { at baseline }\end{array}$ & $\begin{array}{l}45 \\
(90.0)\end{array}$ & \\
\hline $\begin{array}{l}\text { Total number of patients who } \\
\text { shifted from HE Grade } 3 \text { to } \leq 2 \\
\text { Grade* }\end{array}$ & $\begin{array}{l}43 \\
(95.5)\end{array}$ & $<0.0001$ \\
\hline $\begin{array}{l}\text { Total number of patients who had } \\
\text { HE Grade } 4 \text { at baseline }\end{array}$ & $\begin{array}{l}5 \\
(10.0)\end{array}$ & \\
\hline $\begin{array}{l}\text { Total number of patients who } \\
\text { shifted from HE Grade } 4 \text { to } \leq 2 \\
\text { Grade* }\end{array}$ & $\begin{array}{l}2 \\
(40.0)\end{array}$ & $<0.0001$ \\
\hline
\end{tabular}

HE $=$ Hepatic encephalopathy

* Percentage was calculated based on total number of subjects available within each category.

** Chi-square test was used.

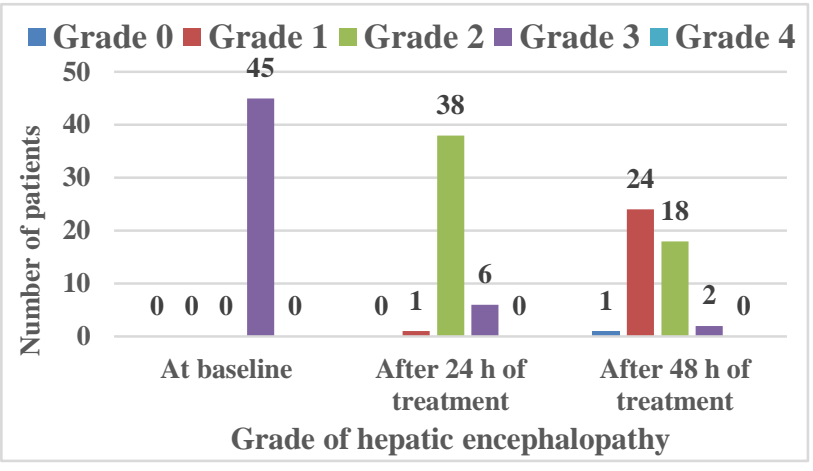

Figure 2: Grade shifts in patients with Grade 3 at baseline ( $n=45)$ after $24 \mathrm{~h}$ and $48 \mathrm{~h}$ of treatment with lactulose retention enema.

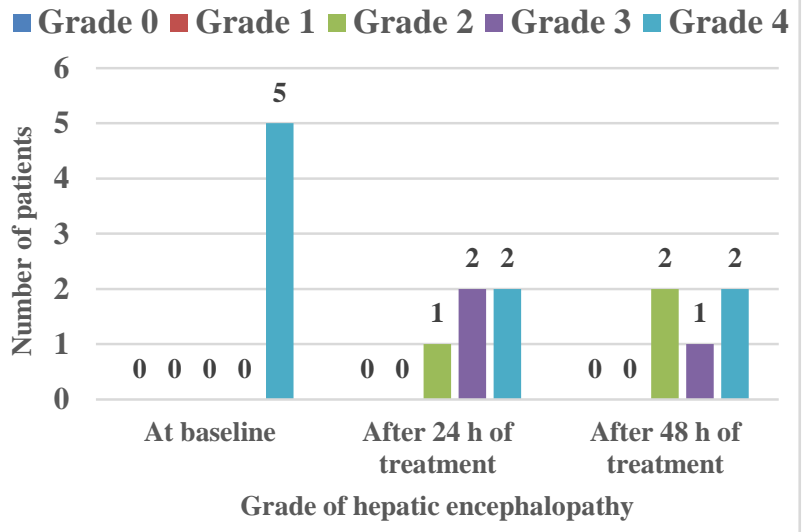

Figure 3: Grade shifts in patients with Grade 4 at baseline $(n=5)$ after $24 \mathrm{~h}$ and $48 \mathrm{~h}$ of treatment with lactulose retention enema.

Out of 50 patients, $1(2 \%)$ patient was noted with Grade 1, $39(78 \%)$ patients were noted with Grade 2, $8(16 \%)$ patients were noted with Grade 3, and 2 (4\%) patients were noted with Grade 4 after $24 \mathrm{~h}$ of treatment. After another $24 \mathrm{~h}$ (i.e. $48 \mathrm{~h}$ of treatment), further improvement was noted in grades with $1(2 \%)$ patient at Grade 0,24 (48\%) patients at Grade 1, $20(40 \%)$ patients at Grade 2, $3(6 \%)$ patients at Grade 3, and only $2(4 \%)$ patients at Grade 4 (Figure 4).

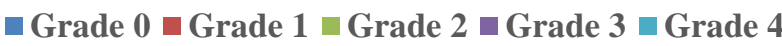

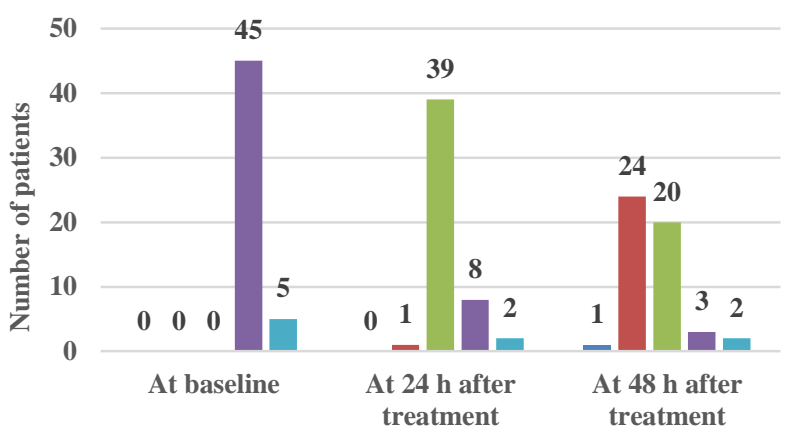

Grade of hepatic encephalopathy

Figure 4: Grade shifts in total number of patients with Grade 3 and $4 \mathrm{HE}(\mathrm{n}=50)$ from baseline till $24 \mathrm{~h}$ and $48 \mathrm{~h}$ of treatment with lactulose retention enema.

Time to complete reversal of Grade 3 and $4 \mathrm{HE}$ after administration of lactulose retention enema

Out of $45(90 \%)$ patients who achieved complete reversal of Grade 3 and $4 \mathrm{HE}$ after treatment, 39 (86.7\%) patients attained complete reversal between 20-24 $\mathrm{h}$ and 6 $(13.3 \%)$ patients in $48 \mathrm{~h}$. The results showed a mean time of $25.39 \pm 8.85 \mathrm{~h}$ for complete reversal of Grade 3 and 4 $\mathrm{HE}$ after administration of lactulose retention enema. 
Mortality in patients treated with lactulose retention enema

Mortality was reported in $6(12.0 \%)$ HE patients treated with lactulose retention enema as per the hospital's protocol. The deaths of these patients were considered to be related to the underlying disease and/or precipitating factors, and unrelated to the administration of lactulose retention enema as per the investigator's discretion. The cause of death is reported in Table 3.

Table 3: Total number of deaths and cause of deaths that occurred in the $\mathrm{HE}$ patients.

\begin{tabular}{|c|c|}
\hline & $\mathrm{n}=\mathbf{5 0}$ \\
\hline Total number of deaths $\mathrm{n}(\%)$ & $6(12.0)$ \\
\hline \multicolumn{2}{|l|}{ Cause of death, $n(\%)$} \\
\hline $\begin{array}{l}\text { Acute on chronic liver failure with sepsis } \\
\text { with septic shock with multi-organ failure }\end{array}$ & $1(2.00)$ \\
\hline $\begin{array}{l}\text { Refractory shock with MODS with } \\
\text { spontaneous bacterial peritonitis; } \\
\text { Decompensated LLD with PHTN }\end{array}$ & $1(2.00)$ \\
\hline Sepsis shock with multi-organ failure & $1(2.00)$ \\
\hline $\begin{array}{l}\text { Sepsis, shock and MOFS, sudden } \\
\text { bradycardia }\end{array}$ & $1(2.00)$ \\
\hline Septic shock with multi-organ failure & $1(2.00)$ \\
\hline $\begin{array}{l}\text { Decompensated alcoholic liver disease } \\
\text { with sepsis }\end{array}$ & $1(2.00)$ \\
\hline
\end{tabular}

\section{Exploratory endpoints}

\section{Reduction in blood ammonia level from baseline}

Blood ammonia level analyzed for 28 patients at baseline was $138.5 \pm 57.18 \mu \mathrm{g} / \mathrm{dL}$. This reduced to $80.73 \pm 26.16$ $\mu \mathrm{g} / \mathrm{dL}$ after administration of lactulose retention enema $(\mathrm{n}=4)$. A statistically significant $(p=0.0011)$ reduction in ammonia levels from baseline to end of study period (48 h) was observed $(-70.6 \pm 11.32 \mu \mathrm{g} / \mathrm{dL})$.

\section{Duration of hospital stay due to $H E$}

The mean duration of hospital stay due to $\mathrm{HE}$ was $229.4 \pm 147.64$ h. Of the 50 patients, $24(48 \%)$ patients stayed in the hospital for 5-10 days; 11 (22\%) patients stayed in the hospital for 1-5 days; $11(22 \%)$ patients stayed in the hospital for 10-20 days; and 4 (8\%) patients stayed in the hospital for 20 to 30 days due to HE.

\section{Safety endpoints}

Overall, four non-serious ADRs in 2 (4\%) patients and one complication (defined as potential adverse effect associated with the use of rectal device) in $1(2 \%)$ patient were noted during the study. The observed non-serious ADRs were as follows: diarrhea, abdominal discomfort, abdominal fullness and discomfort. These ADRs were either considered to be sufficiently described in the section on undesirable effects in local label and/or associated with the method of administration as a retention enema. Mild rectal bleeding due to unstrapped rectal enema was the complication associated with the use of rectal device employed for the application of the lactulose retention enema kit. While the complication and ADRs diarrhea and abdominal discomfort resolved, patient noted with abdominal fullness and discomfort did not recover and these ADRs were ongoing at the time of data capture. There were no serious ADRs during the study.

\section{DISCUSSION}

The present study demonstrated complete reversal of Grade 3 and $4 \mathrm{HE}$ in a significant number of Indian cirrhotic patients after 24 and $48 \mathrm{~h}$ of treatment with lactulose retention enema. Moreover, significant reduction in blood ammonia level was observed in patients at the end of the study period. Lactulose retention enema was found to be well tolerated with no serious ADRs reported.

Lactulose was administered as a retention enema (300 $\mathrm{mL}$ of lactulose mixed with $700 \mathrm{~mL}$ of portable water) in a right lateral position. The enema was to be retained for 30-60 minutes and repeated every 4-6 h until the patient was able to take oral medication. This was consistent with a previous study where lactulose has shown to be effective as a retention enema and in line with the local label. $^{14,16}$

Complete reversal of Grade 3 and $4 \mathrm{HE}$ was observed in a significant proportion of patients after 24 and $48 \mathrm{~h}$ of lactulose retention enema $(\mathrm{p}<0.0001)$. Similar improvements in clinical and electroencephalographic manifestations of $\mathrm{HE}$ have been noted in HE patients treated with lactulose enema in various other studies worldwide. $^{10-13}$ Oral lactulose has been shown to be effective in primary prevention of overt $\mathrm{HE}$ as well as secondary prevention of HE. ${ }^{17,18}$ Since Grade 3 and $4 \mathrm{HE}$ patients are in a comatose stage; enemas may be considered as a better option for such patients, as administering oral medication may not be possible in Grade 3 and $4 \mathrm{HE}$ patients because of unconsciousness and altered sensorium in such patients. ${ }^{6,19}$ A prospective trial in patients with episodic HE revealed significantly higher number of patients with improved West Haven grading who were treated with lactulose enema as compared to the plain (tap water) enema (62\% vs. $15 \%$, $\mathrm{p}$-value $=0.001) .{ }^{14}$

The result of the present study has shown that the grade shifts from Grade 3-4 to $\leq$ Grade 2 were statistically significant after 24 and $48 \mathrm{~h}$ of treatment with lactulose enema $(\mathrm{p} \leq 0.0001)$. Similar results were reported in a previous study where a significant grade shift of 1.46 was observed with lactulose enema after $48 \mathrm{~h}$ of treatment as 
compared to grade shift of 0.38 with plain enema ( $\mathrm{p}$ value $=0.018$ ) in patients with episodic HE. ${ }^{14}$

Our study showed complete reversal of Grade 3 and 4 HE as well as grade shifts from Grade 3 and 4 at baseline to lower grades in a short duration of time after administration of lactulose retention enema. Similar results were observed in the past where improvement in the clinical grade of coma was noted in HE patients within $12 \mathrm{~h}$ of treatment with lactulose enema. ${ }^{11}$ Raza et al. also revealed similar findings with a statistically significant improvement at 48 hours in the West Haven encephalopathy grading in those administered lactulose enema, however there was no statistically significant changes in those given plain enema. ${ }^{14}$ This highlights the importance of lactulose enemas in the patients with Grade 3 and $4 \mathrm{HE}$ requiring immediate treatment.

In the present study, blood ammonia levels significantly $(\mathrm{p}=0.0011)$ reduced by $70.6 \pm 11.32 \mu \mathrm{g} / \mathrm{dL}$ from baseline to end of treatment with lactulose retention enema. Reductions in ammonia levels have been observed with lactulose enemas in previous studies as well. ${ }^{10-13}$ In a previous study, a rapid decrease in blood ammonia levels has been observed within two hours of treatment with lactulose enema during the treatment of acute portal systemic encephalopathy in cirrhotic patients (baseline: $294.7 \pm 93.4 \mu \mathrm{g} / 100 \mathrm{~mL} ; 2 \mathrm{~h}$ post-treatment: $154.5 \pm 46.0$ $\mu \mathrm{g} / 100 \mathrm{~mL} ; \mathrm{p}$-value $<0.001){ }^{12}$

In the present study, majority of the HE patients stayed in hospital for less than 10 days. In addition, only four nonserious ADRs in two patients (diarrhea, abdominal discomfort, abdominal fullness and discomfort) and one complication associated with the use of rectal device in one patient (mild rectal bleeding due to unstrapped rectal enema) were reported during the study. The study reported a mortality of $12 \%$ of which no single death was attributed to lactulose enema as per the investigator's assessment. Another study with 31 patients reported three deaths in Grade 4 encephalopathy; two in the group administered plain water enema $(n=13)$ and one in patients administered lactulose enema $(n=18)$ and not considered as failure of treatment. ${ }^{14}$

Grade 3 and 4 HE patients carry a high risk of mortality due to their underlying liver disease and precipitating factors. Although it is not known if Grade 3 and $4 \mathrm{HE}$ as such are responsible for the mortality, it is essential to minimize the duration of coma. ${ }^{14}$

This study being carried out in Grade 3 and Grade 4 HE patients in Indian population with comparatively large sample size, observed that lactulose retention enema is effective and well-tolerated in patients with Grade 3 and Grade 4 HE within both 24 and 48 hours of treatment.

Lactulose is a well-accepted first-line treatment for HE as per clinical practice guidelines and as per practice guidelines by American College of Gastroenterology lactulose retention enema is to be administered in the recommended volume and concentration to patients of grades 3 and $4 \mathrm{HE}^{3,7,20}$ The present study was conducted to better understand the treatment of $\mathrm{HE}$ with lactulose retention enema, and generate data on the effectiveness and safety of lactulose retention enema in Indian patients. In conclusion, lactulose retention enema demonstrated reversal of Grade 3 and $4 \mathrm{HE}$ in a significant number of patients within both 24 and 48 hours of treatment, along with the reduction of blood ammonia levels. The study also demonstrated that treatment with lactulose retention enema was well-tolerated. Considering oral drugs might not be useful in the management of grade 3 and $4 \mathrm{HE}$ where the patients are unable to take oral medications, this study further strengthens the efficacy and safety data of lactulose enema in patients with grade 3 and grade 4 HE. This study, thus, confirms the positive benefit-risk profile of lactulose administration as a retention enema along with its role in the management of grade 3 and grade $4 \mathrm{HE}$. In future, long-term studies with larger sample size are warranted in real time clinical settings to validate our findings.

\section{ACKNOWLEDGEMENTS}

The authors acknowledge Tech Observer India Limited, New Delhi for site management operations and data management services, and Turacoz Healthcare Solutions, New Delhi for writing support.

Funding: The research was sponsored by Abbott Product Operations, AG, Allschwil, Switzerland

Conflict of interest: Dr. Sanjay Choudhari and Dr. Dyotona Sen Roy are employees of Abbott India Ltd. Dr. Kaushal Madan, Dr. Praveen Sharma and Dr. Neeraj Saraf have received research funding from Abbott India Ltd as investigators

Ethical approval: The study protocol and amendments were reviewed and approved by the ethics committee at each site, with respect to ethical, scientific, and medical appropriateness of the study. The study has been registered on clinical trials.gov, with reference number NCT02377947

\section{REFERENCES}

1. Shawcross DL, Dunk AA, Jalan R, Kircheis G, de Knegt RJ, Laleman W, et al. How to diagnose and manage hepatic encephalopathy: a consensus statement on roles and responsibilities beyond the liver specialist. Eur J Gastroenterol Hepatol. 2016;28:146-52.

2. Poordad FF. Review article: the burden of hepatic encephalopathy. Aliment Pharmacol Ther. 2007;25:3-9.

3. Vilstrup H, Amodio P, Bajaj J, Cordoba J, Ferenci P, Mullen KD, et al. Hepatic encephalopathy in chronic liver disease: 2014 practice guideline by the American Association for the Study of Liver 
Diseases and the European Association for the Study of the Liver. J Hepatol. 2014;61:642-59.

4. Jawaro T, Yang A, Dixit D, Bridgeman MB. Management of Hepatic Encephalopathy: A Primer. Ann Pharmacother. 2016;50:569-77.

5. Wong RJ, Gish RG, Ahmed A. Hepatic encephalopathy is associated with significantly increased mortality among patients awaiting liver transplantation. Liver Transpl. 2014;20:1454-61.

6. Prakash R, Mullen KD. Mechanisms, diagnosis and management of hepatic encephalopathy. Nat Rev Gastroenterol Hepatol. 2010;7:515-25.

7. Leise MD, Poterucha JJ, Kamath PS, Kim WR. Management of hepatic encephalopathy in the hospital. Mayo Clin Proc. 2014;89:241-53.

8. Al Sibae MR, McGuire BM. Current trends in the treatment of hepatic encephalopathy. Ther Clin Risk Manag. 2009;5:617-26.

9. Sharma P, Sharma BC. Management of overt hepatic encephalopathy. J Clin Exp Hepatol. 2015;5:S82-7.

10. Uribe M, Campollo O, Vargas F, Ravelli GP, Mundo F, Zapata L, et.al. Acidifying enemas (lactitol and lactose) vs. nonacidifying enemas (tap water) to treat acute portal-systemic encephalopathy: a doubleblind, randomized clinical trial. Hepatology. 1987;7:639-43.

11. Kersh ES, Rifkin H. Lactulose Enemas. Ann Intern Med. 1973;78:81-84.

12. Van Waes L, van Egmond J, Demeulenaere L. Emergency treatment of portal-systemic encephalopathy with lactulose enemas. A controlled study. Acta Clin Belg. 1979;34:122-9.

13. Ratnaike RN, Hicks EP, Hislop IG. The rectal administration of lactulose. Aust N Z J Med. 1975;5:137-40.
14. Raza MA, Bhatti RS, Akram J. Effect of rectal lactulose administration with oral therapy on time to recovery from hepatic encephalopathy: a randomized study. Ann Saudi Med. 2004;24:374-7.

15. Sharma P, Sharma BC. Management Patterns of Hepatic Encephalopathy: A Nationwide Survey in India. J Clin Exp Hepatol. 2015;5:199-203.

16. Lactulose Solution USP (Duphalac $\AA$ and Duphalac $\AA$ Enema) [drug label]. India: Abbott India Limited; 2014.

17. Sharma P, Sharma BC, Agrawal A, Sarin SK. Primary prophylaxis of overt hepatic encephalopathy in patients with cirrhosis: an open labeled randomized controlled trial of lactulose versus no lactulose. J Gastroenterol Hepatol. 2012;27:1329-35.

18. Sharma BC, Sharma P, Agrawal A, Sarin SK. Secondary prophylaxis of hepatic encephalopathy: an open-label randomized controlled trial of lactulose versus placebo. Gastroenterology. 2009;137:885-91.

19. Phongsamran PV, Kim JW, Cupo Abbott J, Rosenblatt A. Pharmacotherapy for hepatic encephalopathy. Drugs. 2010;70:1131-48.

20. Blei AT, Córdoba J. Practice Parameters Committee of the American College of Gastroenterology. Hepatic Encephalopathy. Am J Gastroenterol. 2001;96:1968-76.

Cite this article as: Madan K, Sharma P, Saraf N, Choudhari S, Roy DS. Effectiveness and safety of lactulose retention enema in cirrhotic patients with grade 3 or grade 4 hepatic encephalopathy. Int $\mathbf{J}$ Basic Clin Pharmacol 2017;6:365-72. 